\title{
Fintech investments in European banks: a hybrid IT2 fuzzy multidimensional decision-making approach
}

\author{
Gang Kou', Özlem Olgu Akdeniz $2^{*} \mathbb{D}$, Hasan Dinçer ${ }^{3}$ and Serhat Yüksel ${ }^{3}$
}

\author{
${ }^{*}$ Correspondence: \\ oolgu@ku.edu.tr \\ ${ }^{2}$ College of Administrative \\ Sciences and Economics, Koç \\ University, Rumeli Feneri Yolu, \\ Sarıyer, Istanbul 34450, Turkey \\ Full list of author information \\ is available at the end of the \\ article
}

\begin{abstract}
Financial technology (Fintech) makes a significant contribution to the financial system by reducing costs, providing higher quality services and increasing customer satisfaction. Hence, new studies play an essential role to improve Fintech investments. This study evaluates Fintech-based investments of European banking services with an application of an original methodology that considers interval type-2 (IT2) fuzzy decision-making trial and evaluation laboratory and IT2 fuzzy TOPSIS models. Empirical findings are controlled for consistency by applying the VIKOR method. Moreover, we conduct a sensitivity analysis by considering six distinct cases. This study contributes to the existing literature by identifying the most important Fintech-based investment alternatives to improve the financial performance of European banks. Our empirical findings illustrate that results are coherent, reliable, and identify "competitive advantage" as the most important factor among Fintech-based determinants. Moreover, "payment and money transferring systems" are the most important Fintech-based investment alternatives. It is recommended that, among Fintech-based investments, European banks should mainly focus on payment and money transferring alternatives to attract the attention of customers and satisfy their expectations. This is also believed to have a positive impact on the ease of bank' receivable collection. Another important point is that Fintech-based investments in money transferring systems could help to decrease costs.
\end{abstract}

Keywords: Financial technology, European banking industry, Interval type-2 fuzzy TOPSIS, DEMATEL

\section{Introduction}

Financial technology (Fintech) is the process of accomplishing technological investments to improve financial operations. It helps firms, including banks, to have a competitive advantage mainly by decreasing costs and increasing efficiency (Zhang and Yang 2019). Fintech is recognized as one of the most important innovations in the financial industry and is evolving at a rapid pace. Fintech promises to reshape the financial industry by cutting costs, improving the quality of financial services, and creating a more diverse and stable financial landscape (FinTech Revolution 2016). Moreover, the world has been battling the Covid 19 pandemic since the beginning of 2020, which is creating financial and author(s) and the source, provide a link to the Creative Commons licence, and indicate if changes were made. The images or other third party material in this article are included in the article's Creative Commons licence, unless indicated otherwise in a credit line to the material. If material is not included in the article's Creative Commons licence and your intended use is not permitted by statutory regulation or exceeds the permitted use, you will need to obtain permission directly from the copyright holder. To view a copy of this licence, visit http:// creativecommons.org/licenses/by/4.0/. 
psychological distress on sectors and economies. As a result, technology and innovation usage massively increased to eliminate the challenges caused by numerous precautions taken by governments such as local and/or national lockdowns. At this point, Fintech applications have stepped forward to catalyze businesses and individual processes. It provides important advantages such as strengthening businesses, processing big data to meaningful data, being universal, cheaper, and more secure compared to conventional methods (Lee and Shin 2018). In addition, Fintech eliminates traditional intermediaries while offering financial services (Thakor 2020). High operational costs are a challenging problem for all sectors exclusively for financial services. Since the beginning of the lockdown in Europe, the usage of Fintech applications has increased by 72 percent (Moden and Neufeld 2020). The recent global trends and the need to have quicker and cost-effective access to banking services has been the ultimate motivation of this research.

Moreover, developing global trends in international trade has had an important influence on the critical role of the global banking sector over recent years. Banks experience a challenge in terms of finding the right Fintech investments to increase their competitive power and satisfy demand of new customers in various countries (Cornaggia et al. 2015). The strategic location of Europe in terms of international trade can be suggested as one of the most important reasons for boosted competition in the European banking sector. With the purpose of handling this challenge, European banks pay an enhanced attention to research and development, customer satisfaction, new product development and organizational efficiency (Căpraru et al. 2020).

In this respect, we suggest numerous investment alternatives to enrich Fintech applications in banking. The first is increasing the effectiveness of money transferring systems (Shaikh et al. 2017). Banks can minimize the cost of money transfers, which in return provide an opportunity to increase sales volume. Furthermore, Fintech applications have a positive impact on bank payment systems as easy payment systems imply more effective collections of receivables on time (Eyal 2017).

The second alternative is related to savings. If essential technological investments are made, customers can have an opportunity to assess their savings easily (Ferrari 2016). Due to the user-friendly applications of these systems, customers may prefer to work with banks equipped with Fintech opportunities. Third, customers can manage their budget and take loans with less effort and time with the help of Fintech investments (Gozman et al. 2018; Liu et al. 2015). It can be suggested that these factors have a positive influence on the competitive power and organizational efficiency of banks.

Our focus is to assess suitable selection of Fintech-based investments in the European banking sector. In the first step, three financial and three non-financial criteria related to the advantages of Fintech-based investments are defined. Then, five Fintech-based investment alternatives are identified. An interval type-2 (IT2) fuzzy decision-making trial and evaluation laboratory (DEMATEL) is employed for weighting the criteria, followed by an application of an IT2 fuzzy TOPSIS model to rank the investment alternatives. Identifying the importance of Fintech-based investment alternatives helps provide suggestions for future research areas. We argue that payment and money transferring systems are the most important alternatives that play an important role in satisfying customer expectations, easing banks' collection of receivables, and decreasing operational costs. 
First, a hybrid model is considered, which means that different MCDM models are used in both weighting the criteria and ranking the alternatives. However, in non-hybrid models, only one MCDM technique is considered to rank the alternatives (Kumar et al. 2020). In this process, the researchers define the weights of the criteria (Mathew et al. 2020). We therefore suggest that hybrid methods have a positive contribution to the objectivity of the results (Yucesan and Gul 2020). In addition, examining the DEMATEL method in the analysis is another important novelty of this model. There are several approaches used to weight the criteria, such as the analytic hierarchy process (AHP), FUCOM, BWM, and level-based weight assessment (LBWA). However, the main superiority of the DEMATEL in comparison to others is the ability of generating the impactrelation map of the criteria (Xu et al. 2020; Garg 2021). This offers the opportunity to conduct causality evaluation among factors (Zhang et al. 2020a, b; Wang et al. 2020).

Another essential novelty of this proposed model is applying the TOPSIS method to rank the alternatives. Even though there are various methods such as MARCOS, VIKOR, and MABAC that can be considered for this purpose, we suggest the TOPSIS method is more suitable as it identifies distances to both positive and negative ideal solutions (Rani et al. 2020; Dhiman and Deb 2020). As a result, it is very helpful to reach more effective results (Rouyendegh et al. 2020; Ziemba et al. 2020). Moreover, considering IT2 fuzzy sets provides some benefits. To solve the decision-making problems more effectively, there is a strong need for a complex analysis to minimize the uncertainty in this process (Soto et al. 2019; Melin et al. 2012). Pulido et al. (2014) and Du et al. (2020) suggest that IT2 fuzzy sets have a positive influence to handle the uncertainty more effectively. Furthermore, we performed a consistency analysis using the VIKOR method to rank the alternatives, followed by a sensitivity analysis considering six individual cases. Hence, it can be possible to check the coherency and reliability of the empirical results. To the best of our knowledge, this study is the first application of a hybrid IT2 fuzzy multidimensional decision-making approach to identify the Fintech-based investment alternatives for European banks.

We believe the proposed model is relevant and serves the purpose of this study. In the first stage of the evaluation process, Fintech-based determinants are weighted. These factors can have an influence on each other. Instead of the AHP and the analytic network process (ANP), we selected the DAMATEL method as it can process a causality analysis between criteria. Additionally, Fintech-based investment alternatives for European banking services are ranked in the second stage of the analysis. As Fintech-based investment alternatives are crucial for improving the performance of the European banking industry, we carefully applied the TOPSIS and VIKOR approaches to rank the alternatives and for reliability analysis. The recommendations can pave the way for investors and policy makers.

The rest of the paper is organized as follows. "Literature review" section introduces the literature review, followed by the methodology in "Methodology" section. "Empirical findings" section introduces the empirical findings. Section 5 concludes, while highlighting and critically evaluating the empirical findings with suggestions to policymakers. 


\section{Literature review}

\section{Literature on Fintech}

Fintech has become a popular research topic over the last decade, which has been evaluated in different aspects. For instance, Chen and Wu (2019) illustrated that it boosts effective consumer finance in China. Applying a SWOT analysis, the study suggested that Fintech applications have a significant influence on the credit system. Additionally, Zhou et al. (2018) provided supporting evidence for the positive impact of Fintech applications on the effectiveness of credit card systems. Sun (2018) and Chang et al. (2017) also underlined the importance of Fintech investments in the performance of such systems was also underlined.

Some studies focused on the importance of Fintech investment in blockchain systems. Nguyen (2016), Li et al. (2017), and Heiskanen (2017) concluded that Fintech and blockchain systems played a key role in sustainable economic development of countries. Treleaven et al. (2017) and Guo and Liang (2016) also determined that the operations of banking and finance can be simplified with the help of the blockchain system. Additionally, Guo and Liang (2016), Du et al. (2019), and Eyal (2017) investigated the importance of Fintech in banking. They indicated that the blockchain technology provides many advantages to the banking system, such as recording payment and credit information of customers.

Other studies emphasized the relationship between Fintech and payment systems of countries. Thompson (2017) outlined the advantages of mobile money application, which is explained as a new type of Fintech. The author revealed that Fintech mainly contributes to the effectiveness of the payment system. Similarly, Woldmariam et al. (2016) explored the design of Fintech in Ethiopia. In this framework, they evaluated mobile money applications. They argued that Fintech provides ease of operations for money payment systems. Additionally, Yao et al. (2018a, b), Shaikh et al. (2017), and Ramos-de-Luna et al. (2016) concluded that Fintech has a positive influence on companies' payment systems.

In addition, Islamic Fintech is described as an important factor in the literature. For instance, Firmansyah and Anwar (2019) focused on Islamic Fintech and defined it as a new trend in Islamic finance. Via a survey analysis in Singapore and Indonesia, they concluded that investments in technology have a positive influence on the development of Islamic finance. Similarly, Bakar and Rosbi (2018) introduced a technical analysis from an Islamic Fintech perspective. They stated that Fintech investments attracted the attention of Islamic investors. Moreover, Rusydiana (2018) and Firmansyah and Ramdani (2018) suggested that technology-based investments lead to improvement in the Islamic financial system.

Some researchers have also discussed the impact of Fintech on customer satisfaction. Kabakova et al. (2016) analyzed Fintech development in Russia illustrating that it is a significant issue in customer satisfaction. In addition, Komulainen et al. (2018) applied an interview methodology to analyze the impact of Fintech investments on supply chain management. They concluded that Fintech is important to meet customer expectations. Furthermore, Xu and Cheng (2017), Yao et al. (2018a, b), Mittal et al. (2017), and Tan et al. (2018) found that Fintech investments are helpful to improve customers satisfaction. 
In a different aspect, some researchers have examined the relationship between Fintech and competition in the market. Chen (2018) assessed Fintech applications in the USA and China. They concluded that Fintech investments are required to survive in competitive environments. In addition, Liu et al. (2015) determined that Fintech provides easiness in the use of payment systems, trading activities, and credit services. Therefore, it is argued that Fintech investments offer a competitive power for companies. Similarly, Kauffman et al. (2015), Kazan et al. (2018), and Gozman et al. (2018) proposed that companies should make Fintech investments to survive in a competitive environment.

Furthermore, reducing costs is another important outcome of Fintech investment. Zhang and Yang (2019) evaluated the Fintech system in China. They demonstrated that it has an important contribution for companies to decrease their costs and increase their profitability. Arner et al. (2018) also defined Fintech investment as the main source of decreasing costs. Similarly, Ko et al. (2018), Dula and Lee (2017), and Anderson et al. (2017) reached the same conclusion.

Lastly, Fintech is assessed for banking sectors. Nguyen (2016) and Guo and Liang (2016) underlined the importance of Fintech in the organizational efficiency of banks. Eyal (2017) also identified that Fintech plays a key role to increase market value. Moreover, Shaikh et al. (2017) and Ferrari (2016) identified Fintech investments as a significant way to increase sales volume of banks.

\section{Literature on MCDM models}

Yu et al. (2021) introduced an excellent literature review on the AHP and ANP research with an application of bibliometric analysis over the 1982-2018 period. The study reviewed 9859 publications from Web of Science and illustrated important findings about the AHP/ANP research supported with future research suggestions. First, China is identified as the most productive country in terms of publications while the USA is the most highly cited country. Moreover, researchers in Malaysia, England, Iran, Australia, and the USA have the highest level of collaborations. From an institutional perspective, findings illustrated that institutions from China have the highest interest in the AHP/ ANP studies, while from a regional perspective, AHP/ANP related publications in Asia have become popular in recent years.

Lin et al. (2020) also confirmed AHP as a commonly applied method in group decision-making and introduced an aggregated version of the nearest consistent matrices (ANCM). The authors emphasized advantages of the proposed model over other techniques and supported their discussion with empirical findings from two applications.

On the other hand, the DEMATEL and TOPSIS approaches have been applied by numerous researchers in different sectors. Xu et al. (2020) weighted the critical barriers to the development of hydrogen refueling stations in China by considering DEMATEL. Similarly, Feng and Ma (2020) identified the factors that have an influence on the service innovation in manufacturing enterprises using the fuzzy DEMATEL method. In addition, Farooque et al. (2020) used the methodology to analyze the barriers to Blockchainbased life cycle assessment in China. Moreover, Zhang et al. (2020a, b) investigated significant factors of youth unemployment using interval-valued intuitionistic hesitant fuzzy DEMATEL based on 2-tuple linguistic values. Zhong et al. (2020) and Yuan et al. 
(2020) focused on important strategies for renewable energy investments by applying DEMATEL.

Dogan et al. (2019) utilized TOPSIS regarding a corridor selection for locating autonomous vehicles. Furthermore, Demirel et al. (2016) introduced a comparative evaluation for location selection of textile plants in Turkey and ranked alternatives using TOPSIS. Deveci et al. (2020) and Türk et al. (2021) applied the methodology with IT2 fuzzy sets for offshore wind farm development and locating electric charging stations. In addition, Qiu et al. (2020) used TOPSIS to conduct risk evaluation of the wind energy investments in emerging economies. A recent study by Çalık (2021) applied Pythagorean fuzzy TOPSIS for green supplier selection in the era of Industry 4.0.

\section{Rationale of the study}

It is possible to reach some conclusions after conducting this comprehensive review of the literature. First, the popularity of Fintech subjects has increased in the literature, especially in the last years. Many different researchers have focused on the advantages of this system for companies, such as cost minimization and customer satisfaction, by considering different industries. There is a need for new research that provides specific strategies to improve Fintech investments. Hence, this study evaluates Fintechbased investments for European banking services. The literature review also reveals that econometric models, such as regression and cointegration analysis, are considered in most of the studies regarding Fintech. The main limitation of these approaches is that only numerical indicators can be considered. Therefore, different methodologies that can consider both numerical and non-numerical determinants should be used. Hence, the current study proposes a novel model by considering IT2 fuzzy DEMATEL and IT2 fuzzy TOPSIS. These approaches have been used by various studies in the literature. In the current research, these approaches are used together to increase objectivity of the analysis results. Additionally, decision-making problems involve quite complex processes. These methods should also be developed to achieve more accurate and effective results. Thus, these methods are used with IT2 fuzzy sets to handle the uncertainties in this process more effectively.

\section{Methodology}

The model is estimated using an integrated decision-making approach based on IT2 fuzzy sets. IT2 fuzzy DEMATEL is employed to weight the Fintech-based determinants, followed by an application of the TOPSIS with IT2 fuzzy sets to rank the investment alternatives of the European banking sector. Additionally, a comparative analysis is performed using the fuzzy VIKOR method, followed by a sensitivity analysis. The details of the proposed model are illustrated in Fig. 1.

The stages and steps of this proposed model are highlighted as follows.

Stage 1: Weighting the criteria with IT2F-DEMATEL

Step 1: Define the multi-criteria decision-making problem of Fintech-based investments for the European banking sector. 


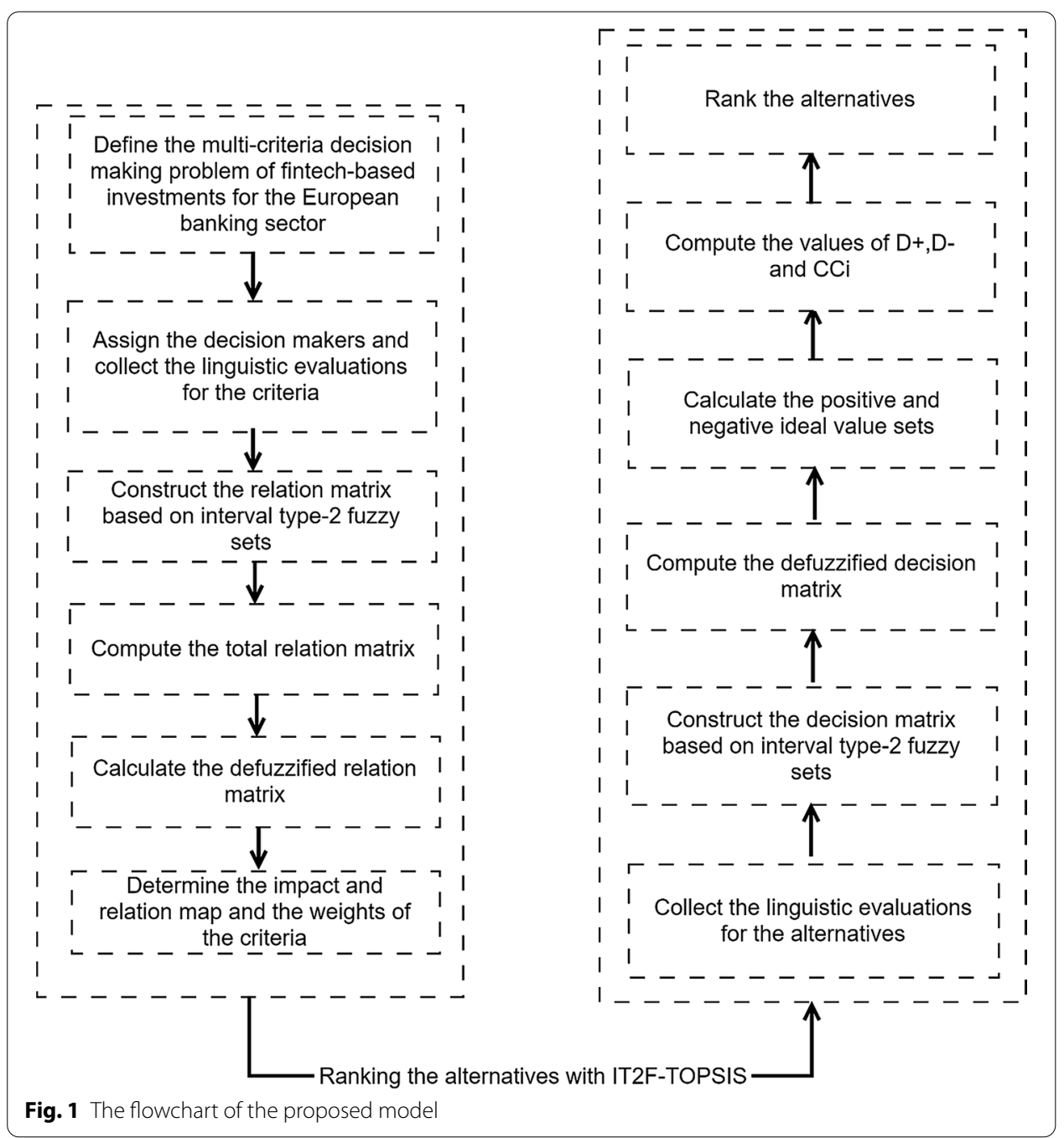

Step 2: Assign the decision-makers and collect the linguistic evaluations for the criteria.

Step 3: Construct the relation matrix based on IT2 fuzzy sets.

Step 4: Compute the total relation matrix.

Step 5: Calculate the defuzzified relation matrix.

Step 6: Determine the impact and relation map and the weights of the crite-

ria.

Stage 2: Ranking the alternatives with IT2F-TOPSIS

Step 7: Collect the linguistic evaluations for the alternatives.

Step 8: Construct the decision matrix based on IT2 fuzzy sets.

Step 9: Compute the defuzzified decision matrix.

Step 10: Calculate the positive and negative ideal value sets.

Step 11: Compute the values of $\mathrm{D}+, \mathrm{D}-$, and $\mathrm{CCi}$.

Step 12: Rank the alternatives. 
The proposed model is a hybrid method that covers an application of the DEMATEL, TOPSIS, and VIKOR, and is suitable for the evaluation of Fintech-based investments of European banking services. It considers six selective criteria that may have an impact on each other. In addition to weighting the criteria, the cause-and-effect relationship of these items should also be investigated. With the help of the DEMATEL method, we generated an impact-relation map. In the final stage of our analysis, Fintech-based investment alternatives are ranked for the European banking services, which is crucial in proposing investment suggestions and policy implications. In this respect, both TOPSIS and VIKOR approaches are adopted to examine the consistency and coherency of the results.

\section{Data and variables}

In Step 1 of our technical analysis, multi-criteria decision-making is defined to construct the model. We evaluated a set of criteria and alternatives based on the relevant literature. The selected criteria for problem definition are introduced in Table 1.

As shown in Table 1, three financial and three non-financial criteria are identified for Fintech-based investments. With respect to the financial criteria, cost management (C1) demonstrates that banks can undertake Fintech investment mainly to decrease operational costs as they can provide banking services at a lower cost. The next criterion, sales volume (C2), indicates that Fintech can have a positive influence on the sales volume. Additionally, increase in market value (C3) provides information that adopting this technology provides opportunity to have a greater market value.

Regarding non-financial dimensions, Fintech investments lead to higher customer satisfaction (C4) due to easily accessible and user-friendly operations. Another important point of Fintech investment is that it provides competitive advantage (C5) for banks. The final criterion, organizational efficiency (C6), explains that considering Fintech helps to improve communication among the departments. Our Fintech-based investment alternatives suggested for the European banking sector are presented in Table 2.

Table 2 introduces our five suggested alternatives for Fintech investments. First, banks can make Fintech investments to money transferring systems (alternative 1).

Table 1 Fintech-based determinants of the European banking sector. Source: Created by the authors

\begin{tabular}{|c|c|c|}
\hline Dimensions & Criteria & References \\
\hline \multirow[t]{3}{*}{ Financial (Dimension 1) } & Cost management (C1) & $\begin{array}{l}\text { Zhang and Yang (2019), Arner et al. (2018), Ko et al. } \\
\text { (2018), Dula and Lee (2017) and Anderson et al. } \\
\text { (2017) }\end{array}$ \\
\hline & Sales volume (C2) & $\begin{array}{l}\text { Shaikh et al. (2017), Ferrari (2016) and Heiskanen } \\
\text { (2017) }\end{array}$ \\
\hline & Increase in market value (C3) & $\begin{array}{l}\text { Eyal (2017), Zhou et al. (2018), Sun (2018) and } \\
\text { Chang et al. (2017) }\end{array}$ \\
\hline \multirow[t]{3}{*}{ Non-financial (Dimension 2) } & Customer satisfaction (C4) & $\begin{array}{l}\text { Kabakova et al. (2016), Komulainen et al. (2018), Xu } \\
\text { and Cheng (2017), Yao et al. (2018a, b), Mittal et al. } \\
\text { (2017) and Tan et al. (2018) }\end{array}$ \\
\hline & Competitive advantage (C5) & $\begin{array}{l}\text { Chen (2018), Liu et al. (2015), Kauffman et al. (2015), } \\
\text { Kazan et al. (2018) and Gozman et al. (2018) }\end{array}$ \\
\hline & Organizational efficiency (C6) & $\begin{array}{l}\text { Nguyen (2016), Guo and Liang (2016), Treleaven } \\
\text { et al. (2017) and Guo and Liang (2016) }\end{array}$ \\
\hline
\end{tabular}


Table 2 Fintech-based investment alternatives for the European banking services. Source: Created by the authors

\begin{tabular}{ll}
\hline Alternatives & References \\
\hline Money transferring (alternative 1) & $\begin{array}{c}\text { Yao et al. (2018a, b), Shaikh et al. (2017) and Ramos-de- } \\
\text { Luna et al. (2016) }\end{array}$ \\
Payments (alternative 2) & Guo and Liang (2016), Du et al. (2019) and Eyal (2017) \\
Savings (alternative 3) & Shaikh et al. (2017) and Ferrari (2016) \\
Budgeting (alternative 4) & Kazan et al. (2018) and Gozman et al. (2018) \\
Borrowings (alternative 5) & Chen (2018), Liu et al. (2015) and Kauffman et al. (2015)
\end{tabular}

Table 3 The details decision makers (DM)

\begin{tabular}{llll}
\hline Decision makers & $\begin{array}{l}\text { Level of } \\
\text { education }\end{array}$ & Experience & Occupation \\
\hline DM1 & Ph.D. & 29 years & $\begin{array}{c}\text { Academic in banking, strategy development and risk } \\
\text { management } \\
\text { Academic in banking, finance, financial development }\end{array}$ \\
DM2 & Ph.D. & $\begin{array}{l}10 \text { years } \\
\text { DM3 }\end{array}$ & \begin{tabular}{l} 
Academic and CFO in a private bank \\
\hline
\end{tabular}
\end{tabular}

This is suggested as a cost cutting application as it removes the burden for customers traveling to a branch and helps save time. This is anticipated to increase banks' sales volume and their revenues.

Second, banks can make Fintech investments to payment systems (alternative 2). If customers can pay their debt easily, banks would have a chance to collect their receivables on time. Third, if bank customers can easily estimate their savings (alternative 3) with the help of Fintech investments, they would prefer to work with these banks. Fourth, banks can make Fintech investments to improve budgeting operations (alternative 4), which can attract the attention of customers. Finally, Fintech investments can be directed to borrowing operations (alternative 5). If customers have easy access to and quick approval for a bank loan, this is expected to increase banks' sales volume and revenues.

A set of criteria in two dimensions is evaluated by the expert team. A total of three decision-makers are appointed to provide their linguistic evaluations for the criteria and alternatives. Decision-makers are experts in the field of research and development in financial services with at least ten years' experience. The details of the experts are reported in Table 3.

Linguistic evaluations for the criteria and alternatives are provided in Tables 4 and 5 .

The values are converted into trapezoidal fuzzy numbers to analyze under the fuzzy environment. Linguistic scales and their IT2 fuzzy numbers are presented in "Appen$\operatorname{dix} \mathrm{A}^{\prime \prime}$

\section{Interval type-2 fuzzy sets}

A type-2 fuzzy set is shown as $\tilde{A}$ while $\mu_{\tilde{A}(x, u)}$ gives information about the type-2 membership function. Details of this process are revealed in Eq. (1) (Soto et al. 2019; Zhou et al. 2020). 


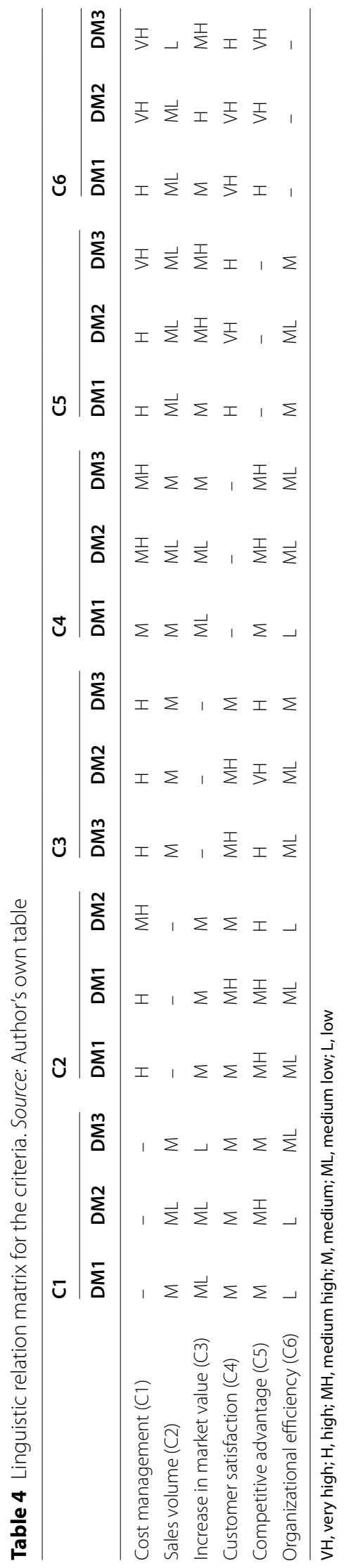




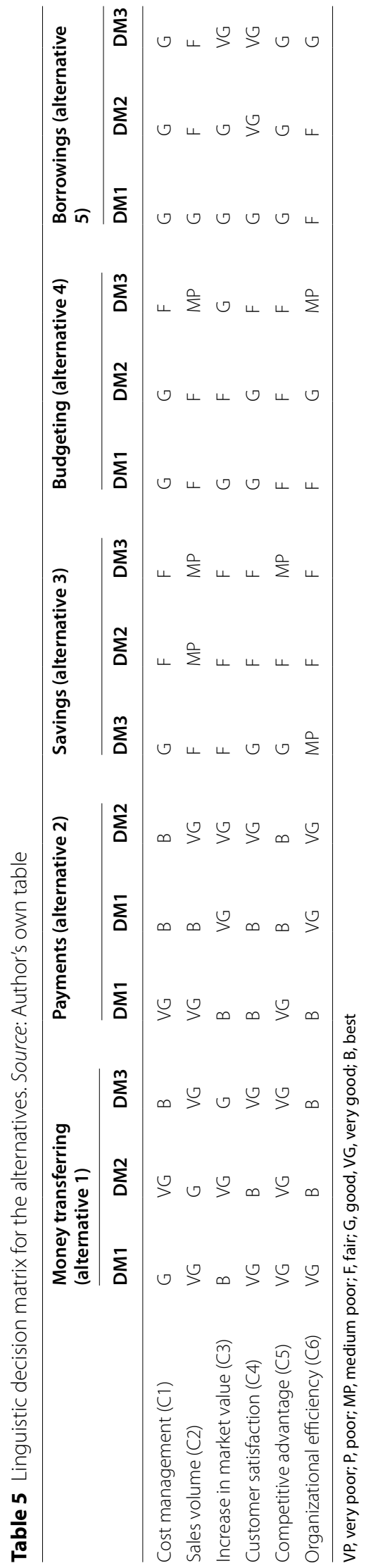




$$
\tilde{A}=\left\{\left((x, u), \mu_{\tilde{A}(x, u)}\right) \mid \forall_{x} \in X, \forall_{u} \in J_{x} \subseteq[0,1]\right\}, \text { or } \tilde{A}=\int_{x \in X} \int_{u \in J_{x}} \mu_{\tilde{A}}(x, u) /(x, u) J_{x} \subseteq[0,1]
$$

Within this context, $\mu_{\tilde{A}}(x, u)$ can take values between 0 and 1 . Moreover, $\iint$ identifies the union over all admissible $x$ and $u$. Regarding the discrete universes, $\int$ can be replaced by $\Sigma$. When all $\mu_{\tilde{A}}(x, u)$ is equal to $1, \tilde{A}$ can be shown ass in the Eq. (2) (Soto et al. 2018).

$$
\tilde{A}=\int_{x \in X} \int_{u \in J_{x}} 1 /(x, u) J_{x} \subseteq[0,1]
$$

Figure 2 provides information about the membership functions of IT2 fuzzy sets (Soto et al. 2014; Qiu et al. 2020).

In this scope, the upper trapezoidal membership function is represented by $\tilde{A}_{i}^{U}$. Additionally, $\tilde{A}_{i}^{L}$ identifies the lower trapezoidal membership function. The details are presented in Eq. (3) (Pulido et al. 2014; Dinçer et al. 2019).

$$
\tilde{A}_{i}=\left(\tilde{A}_{i}^{U}, \tilde{A}_{i}^{L}\right)=\left(\left(a_{i 1}^{U}, a_{i 2}^{U}, a_{i 3}^{U}, a_{i 4}^{U} ; H_{1}\left(\tilde{A}_{i}^{U}\right), H_{2}\left(\tilde{A}_{i}^{U}\right)\right),\left(a_{i 1}^{L}, a_{i 2}^{L}, a_{i 3}^{L}, a_{i 4}^{L} ; H_{1}\left(\tilde{A}_{i}^{L}\right), H_{2}\left(\tilde{A}_{i}^{L}\right)\right)\right)
$$

In this equation, $a_{i 1}^{U}, a_{i 2}^{U}, a_{i 3}^{U}, a_{i 4}^{U}, a_{i 1}^{L}, a_{i 2}^{L}, a_{i 3}^{L}, a_{i 4}^{L}$ are the reference values of the IT2 fuzzy set. $H_{j}\left(\tilde{A}_{i}^{U}\right)$ represents the membership value in the upper trapezoidal membership function whereas $H_{j}\left(\tilde{A}_{i}^{L}\right)$ shows that in the lower trapezoidal membership function. Details are given in Eqs. (4) -(8) (Melin et al. 2012; Du et al. 2020).

$$
\begin{aligned}
\tilde{A}_{1} \oplus \tilde{A}_{2}= & \left(\tilde{A}_{1}^{U}, \tilde{A}_{1}^{L}\right) \oplus\left(\tilde{A}_{2}^{U}, \tilde{A}_{2}^{L}\right)=\left(\left(a_{11}^{U}+a_{21}^{U}, a_{12}^{U}+a_{22}^{U}, a_{13}^{U}+a_{23}^{U}, a_{14}^{U}\right.\right. \\
& \left.+a_{24}^{U} ; \min \left(H_{1}\left(\tilde{A}_{1}^{U}\right), H_{1}\left(\tilde{A}_{2}^{U}\right)\right), \min \left(H_{2}\left(\tilde{A}_{1}^{U}\right), H_{2}\left(\tilde{A}_{2}^{U}\right)\right)\right), \\
& \left.\left(a_{11}^{L}+a_{21}^{L}, a_{12}^{L}+a_{22}^{L}, a_{13}^{L}+a_{23}^{L}, a_{14}^{L}+a_{24}^{L} ; \min \left(H_{1}\left(\tilde{A}_{1}^{L}\right), H_{1}\left(\tilde{A}_{2}^{L}\right)\right), \min \left(H_{2}\left(\tilde{A}_{1}^{L}\right), H_{2}\left(\tilde{A}_{2}^{L}\right)\right)\right)\right) \\
\tilde{A}_{1} \ominus \tilde{A}_{2}= & \left(\tilde{A}_{1}^{U}, \tilde{A}_{1}^{L}\right) \ominus\left(\tilde{A}_{2}^{U}, \tilde{A}_{2}^{L}\right)=\left(\left(a_{11}^{U}-a_{24}^{U}, a_{12}^{U}-a_{23}^{U}, a_{13}^{U}-a_{22}^{U}, a_{14}^{U}\right.\right. \\
& \left.-a_{21}^{U} ; \min \left(H_{1}\left(\tilde{A}_{1}^{U}\right), H_{1}\left(\tilde{A}_{2}^{U}\right)\right), \min \left(H_{2}\left(\tilde{A}_{1}^{U}\right), H_{2}\left(\tilde{A}_{2}^{U}\right)\right)\right), \\
& \left.\left(a_{11}^{L}-a_{24}^{L}, a_{12}^{L}-a_{23}^{L}, a_{13}^{L}-a_{22}^{L}, a_{14}^{L}-a_{21}^{L} ; \min \left(H_{1}\left(\tilde{A}_{1}^{L}\right), H_{1}\left(\tilde{A}_{2}^{L}\right)\right), \min \left(H_{2}\left(\tilde{A}_{1}^{L}\right), H_{2}\left(\tilde{A}_{2}^{L}\right)\right)\right)\right)
\end{aligned}
$$

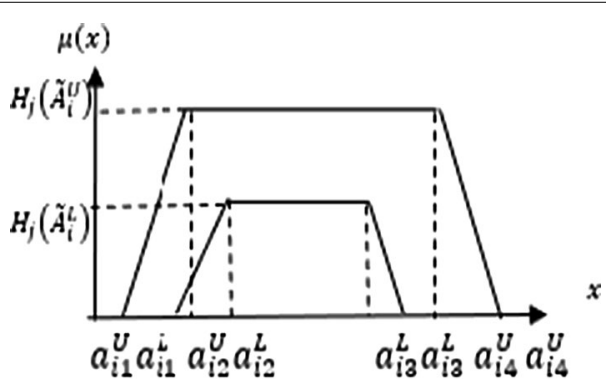

Fig. 2 The trapezoidal membership function of the interval type-2 fuzzy set 


$$
\begin{aligned}
\tilde{A}_{1} \otimes \tilde{A}_{2}= & \left(\tilde{A}_{1}^{U}, \tilde{A}_{1}^{L}\right) \otimes\left(\tilde{A}_{2}^{U}, \tilde{A}_{2}^{L}\right)=\left(\left(a_{11}^{U} \times a_{21}^{U}, a_{12}^{U} \times a_{22}^{U}, a_{13}^{U} \times a_{23}^{U}, a_{14}^{U}\right.\right. \\
& \left.\times a_{24}^{U} ; \min \left(H_{1}\left(\tilde{A}_{1}^{U}\right), H_{1}\left(\tilde{A}_{2}^{U}\right)\right), \min \left(H_{2}\left(\tilde{A}_{1}^{U}\right), H_{2}\left(\tilde{A}_{2}^{U}\right)\right)\right), \\
& \left.\left(a_{11}^{L} \times a_{21}^{L}, a_{12}^{L} \times a_{22}^{L}, a_{13}^{L} \times a_{23}^{L}, a_{14}^{L} \times a_{24}^{L} ; \min \left(H_{1}\left(\tilde{A}_{1}^{L}\right), H_{1}\left(\tilde{A}_{2}^{L}\right)\right), \min \left(H_{2}\left(\tilde{A}_{1}^{L}\right), H_{2}\left(\tilde{A}_{2}^{L}\right)\right)\right)\right)
\end{aligned}
$$

$$
\begin{aligned}
k \tilde{A}_{1}= & \left(k \times a_{11}^{U}, k \times a_{12}^{U}, k \times a_{13}^{U}, k \times a_{14}^{U} ; H_{1}\left(\tilde{A}_{1}^{U}\right), H_{2}\left(\tilde{A}_{1}^{U}\right)\right), \\
& \left(k \times a_{11}^{L}, k \times a_{12}^{L}, k \times a_{13}^{L}, k \times a_{14}^{L} ; H_{1}\left(\tilde{A}_{1}^{L}\right), H_{2}\left(\tilde{A}_{1}^{L}\right)\right) \\
\frac{\tilde{A}_{1}}{k}= & \left(\frac{1}{k} \times a_{11}^{U}, \frac{1}{k} \times a_{12}^{U}, \frac{1}{k} \times a_{13}^{U}, \frac{1}{k} \times a_{14}^{U} ; H_{1}\left(\tilde{A}_{1}^{U}\right), H_{2}\left(\tilde{A}_{1}^{U}\right)\right), \\
& \left(\frac{1}{k} \times a_{11}^{L}, \frac{1}{k} \times a_{12}^{L}, \frac{1}{k} \times a_{13}^{L}, \frac{1}{k} \times a_{14}^{L} ; H_{1}\left(\tilde{A}_{1}^{L}\right), H_{2}\left(\tilde{A}_{1}^{L}\right)\right)
\end{aligned}
$$

\section{IT2F-DEMATEL}

The first stage of hybrid modeling is the application of the DEMATEL method based on IT2 fuzzy sets to measure the relative importance of each Fintech-based determinant. The method provides comprehensive results by obtaining influence degrees of each criterion in addition to the weights of the factors. The first step of the DEMATEL method is to construct the direct-relation matrix. The average values provided by the decision-makers are used to construct the relation matrix. The normalization procedure is then employed in Eqs. (9)-(12) (Xu et al. 2020).

$$
\begin{aligned}
& \tilde{Z}=\left[\begin{array}{ccccc}
0 & \tilde{z}_{12} & \cdots & \cdots & \tilde{z}_{1 n} \\
\tilde{z}_{21} & 0 & \cdots & \cdots & \tilde{z}_{2 n} \\
\vdots & \vdots & \ddots & \cdots & \cdots \\
\vdots & \vdots & \vdots & \ddots & \vdots \\
\tilde{z}_{n 1} & \tilde{z}_{n 2} & \cdots & \cdots & 0
\end{array}\right] \\
& \tilde{Z}=\frac{\tilde{Z}^{1}+\tilde{Z}^{2}+\tilde{Z}^{3}+\ldots \tilde{Z}^{n}}{n} \\
& \tilde{x}_{i j}=\frac{\tilde{z}_{i j}}{r}=\left(\frac{Z_{a_{i j}}}{r}, \frac{Z_{b_{i j}^{\prime}}}{r}, \frac{Z_{c_{i j}^{\prime}}}{r}, \frac{Z_{d_{i j}^{\prime}}}{r} ; H_{1}\left(z_{i j}^{U}\right), H_{2}\left(z_{i j}^{U}\right)\right),\left(\frac{Z_{e_{i j}^{\prime}}}{r}, \frac{Z_{f_{i j}^{\prime}}}{r}, \frac{Z_{g_{i j}^{\prime}}}{r}, \frac{Z_{h_{i j}^{\prime}}}{r} ; H_{1}\left(z_{i j}^{L}\right), H_{2}\left(z_{i j}^{L}\right)\right) \\
& r=\max \left(\max _{1 \leq i \leq n} \sum_{j=1}^{n} Z_{d_{i j}^{\prime}}, \max _{1 \leq i \leq n} \sum_{j=1}^{n} Z_{d_{i j}^{\prime}}\right)
\end{aligned}
$$

The second stage is to compute the total relation matrix using Eqs. (13)-(17) (Garg 2021). 


$$
\begin{aligned}
& X_{\grave{a}}=\left[\begin{array}{ccccc}
0 & a_{12}^{\prime} & \cdots & \cdots & a_{1 n}^{\prime} \\
a_{21}^{\prime} & 0 & \cdots & \cdots & a_{2 n}^{\prime} \\
\vdots & \vdots & \ddots & \cdots & \cdots \\
\vdots & \vdots & \vdots & \ddots & \vdots \\
a_{n 1}^{\prime} & a_{n 2}^{\prime} & \cdots & \cdots & 0
\end{array}\right], \ldots, X_{h}=\left[\begin{array}{ccccc}
0 & h_{12}^{\prime} & \cdots & \cdots & h_{1 n}^{\prime} \\
h_{21}^{\prime} & 0 & \cdots & \cdots & h_{2 n}^{\prime} \\
\vdots & \vdots & \ddots & \cdots & \cdots \\
\vdots & \vdots & \vdots & \ddots & \vdots \\
h_{n 1}^{\prime} & h_{n 2}^{\prime} & \cdots & \cdots & 0
\end{array}\right] \\
& \tilde{T}=\lim _{k \rightarrow \infty} \tilde{X}+\tilde{X}^{2}+\ldots+\tilde{X}^{k} \\
& \tilde{T}=\left[\begin{array}{ccccc}
\tilde{t}_{11} & \tilde{t}_{12} & \cdots & \cdots & \tilde{t}_{1 n} \\
\tilde{t}_{21} & \tilde{t}_{22} & \cdots & \cdots & \tilde{t}_{2 n} \\
\vdots & \vdots & \ddots & \ldots & \ldots \\
\vdots & \vdots & \vdots & \ddots & \vdots \\
\tilde{t}_{n 1} & \tilde{t}_{n 2} & \cdots & \cdots & \tilde{t}_{n n}
\end{array}\right] \\
& \tilde{t}_{i j}=\left(a_{i j}^{\prime \prime}, b_{i j}^{\prime \prime}, c_{i j}^{\prime \prime}, d_{i j}^{\prime \prime} ; H_{1}\left(\tilde{t}_{i j}^{U}\right), H_{2}\left(\tilde{t}_{i j}^{U}\right)\right),\left(e_{i j}^{\prime \prime}, f_{i j}^{\prime \prime}, g_{i j}^{\prime \prime}, h_{i j}^{\prime \prime} ; H_{1}\left(\tilde{t}_{i j}^{L}\right), H_{2}\left(\tilde{t}_{i j}^{L}\right)\right) \\
& {\left[a_{i j}^{\prime \prime}\right]=X_{\grave{a}} \times\left(I-X_{\grave{a}}\right)^{-1}, \ldots,\left[h_{i j}^{\prime \prime}\right]=X_{\grave{h}} \times\left(I-X_{\grave{h}}\right)^{-1}}
\end{aligned}
$$

The defuzzified values of the total relation matrix are then calculated. The impact and degree of relation among each criterion is measured using Eqs. (18) - (21) (Zhang et al. 2020a, b).

$$
D e f_{T}=\frac{\frac{\left(u_{U}-l_{U}\right)+\left(\beta_{U} \times m_{1 U}-l_{U}\right)+\left(\alpha U \times m_{2 U}-l_{U}\right)}{4}+l_{U}+\left[\frac{\left(u_{L}-l_{L}\right)+\left(\beta_{L} \times m_{1 L}-l_{L}\right)+\left(\alpha_{L} \times m_{2 L}-l_{L}\right)}{4}+l_{L}\right]}{2}
$$

$$
\operatorname{Def}_{T}=T=\left[t_{i j}\right]_{n \times n}, i, j=1,2, \ldots, n
$$

$$
\begin{aligned}
& \tilde{D}_{i}^{d e f}=r=\left[\sum_{j=1}^{n} t_{i j}\right]_{n \times 1}=\left(r_{i}\right)_{n \times 1}=\left(r_{1}, \ldots, r_{i}, \ldots, r_{n}\right) \\
& \tilde{R}_{i}^{d e f}=y=\left[\sum_{i=1}^{n} t_{i j}\right]_{1 \times n}^{\prime}=\left(y_{j}\right)_{1 \times n}^{\prime}=\left(y_{1}, \ldots, y_{i}, \ldots, y_{n}\right)
\end{aligned}
$$

where $\tilde{D}_{i}^{\text {def }}$ and $\tilde{R}_{i}^{\text {def }}$ represent the sum of all vector rows and columns, respectively. The influence degrees are presented as $\left(\tilde{D}_{i}-\tilde{R}_{i}\right)^{\text {def }}$ and the relative importance is computed by $\left(\tilde{D}_{i}+\tilde{R}_{i}\right)^{\text {def }}$ (Wang et al. 2020). 


\section{IT2F-TOPSIS}

The integrated decision-making model continues with an application of the IT2 fuzzy TOPSIS method. The method handles negative and positive ideal solutions in the multicriteria decision-making problem and measures distances from the ideal solution (Rani et al. 2020).

The first step of TOPSIS is to construct the decision matrix. Average scores of the decision-makers are used to contract the fuzzy decision matrix in Eqs. (22)-(23) (Dhiman and Deb 2020).

$$
\begin{array}{r}
C_{1} C_{2} C_{3} \ldots \\
A_{i j}=\begin{array}{c}
A_{1} \\
A_{2} \\
A_{3} \\
\vdots \\
A_{m}
\end{array}\left[\begin{array}{lllll}
x_{11} & x_{12} & x_{13} & \ldots & x_{1 n} \\
x_{21} & x_{22} & x_{23} & \ldots & x_{2 n} \\
x_{31} & x_{32} & x_{33} & \ldots & x_{3 n} \\
\vdots & \vdots & \ddots & \ldots \\
x_{m 1} & x_{m 2} & x_{m 3} & \ldots & x_{m n}
\end{array}\right] \\
X_{i j}=\frac{1}{K}\left[\sum_{e=1}^{n} X_{i j}^{e}\right], \quad i=1,2,3, \ldots, m
\end{array}
$$

where the aggregated fuzzy values are $\mathrm{X}_{\mathrm{ij}}$, and the number of decision-makers is defined as $K$.

The second step is to compute the defuzzified values of the decision matrix following Chen and Lee (2010) in Eqs. (24)-(27) (Rouyendegh et al. 2020).

$$
\begin{aligned}
\operatorname{Def}\left(x_{i j}\right)=\operatorname{Rank}\left(\tilde{x}_{i j}\right)_{m \times n}= & M_{1}\left(\tilde{A}_{i}^{U}\right)+M_{1}\left(\tilde{A}_{i}^{L}\right)+M_{2}\left(\tilde{A}_{i}^{U}\right) \\
& +M_{2}\left(\tilde{A}_{i}^{L}\right)+M_{3}\left(\tilde{A}_{i}^{U}\right)+M_{3}\left(\tilde{A}_{i}^{L}\right) \\
- & \frac{1}{4}\left(S_{1}\left(\tilde{A}_{i}^{U}\right)+S_{1}\left(\tilde{A}_{i}^{L}\right)\right. \\
& +S_{2}\left(\tilde{A}_{i}^{U}\right)+S_{2}\left(\tilde{A}_{i}^{L}\right)+S_{3}\left(\tilde{A}_{i}^{U}\right) \\
& \left.+S_{3}\left(\tilde{A}_{i}^{L}\right)+S_{4}\left(\tilde{A}_{i}^{U}\right)+S_{4}\left(\tilde{A}_{i}^{L}\right)\right) \\
& +H_{1}\left(\tilde{A}_{i}^{U}\right)+H_{1}\left(\tilde{A}_{i}^{L}\right)+H_{2}\left(\tilde{A}_{i}^{U}\right)+H_{2}\left(\tilde{A}_{i}^{L}\right) \\
M_{p}\left(\tilde{A}_{i}^{j}\right)=\left(a_{i p}^{j}+a_{i(p+1)}^{j}\right) / 2 &
\end{aligned}
$$

where $M_{p}\left(\tilde{A}_{i}^{j}\right)$ is the average of $a_{i p}^{j}$ and $a_{i(p+1)}^{j}, 1 \leq p \leq 3$,

$$
S_{q}\left(\tilde{A}_{i}^{j}\right)=\sqrt{\frac{1}{2} \sum_{k=q}^{q+1}\left(a_{i k}^{j}-\frac{1}{2} \sum_{k=q}^{q+1} a_{i k}^{j}\right)^{2}}
$$

where $S_{q}\left(\tilde{A}_{i}^{j}\right)$ is the standard deviation of $a_{i q}^{j}$ and $a_{i(q+1)}^{j}, 1 \leq q \leq 3$, 
Table 6 Weighting results of criteria and dimensions. Source: Author's calculations

\begin{tabular}{llllcll}
\hline Criteria & $\tilde{D}_{i}^{\text {def }}$ & $\tilde{R}_{i}^{\text {def }}$ & $\left(\tilde{D}_{i}+\tilde{R}_{i}\right)^{\text {def }}$ & $\left(\tilde{D}_{i}-\tilde{R}_{i}\right)^{\text {def }}$ & $\begin{array}{l}\text { Criterion } \\
\text { weights }\end{array}$ & Dimension weights \\
\hline C1 & 2.10 & 1.02 & 3.12 & 1.07 & 0.172 & Financial (0.48) \\
C2 & 1.11 & 1.52 & 2.63 & -0.40 & 0.145 & \\
C3 & 1.24 & 1.71 & 2.94 & -0.47 & 0.163 & \\
C4 & 1.83 & 1.26 & 3.09 & 0.57 & 0.171 & Non-financial (0.52) \\
C5 & 1.91 & 1.64 & 3.55 & 0.27 & 0.196 & \\
C6 & 0.87 & 1.91 & 2.78 & -1.04 & 0.153 & \\
\hline
\end{tabular}

$$
S_{4}\left(\tilde{A}_{i}^{j}\right)=\sqrt{\frac{1}{4} \sum_{k=1}^{4}\left(a_{i k}^{j}-\frac{1}{4} \sum_{k=1}^{4} a_{i k}^{j}\right)^{2}}
$$

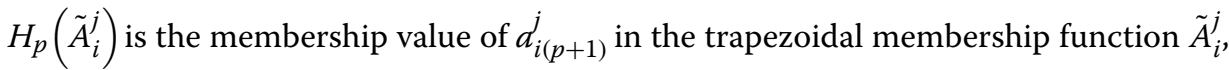
$1 \leq p \leq 2, j \in\{U, L\} 1 \leq i \leq n$. The third step of the TOPSIS method is to compute the closeness coefficient $\left(\mathrm{CC}_{\mathrm{i}}\right)$ in Eqs. (28)-(32) (Petrovic and Kankaras 2020).

$$
\begin{aligned}
& A^{+}=\left\{v_{1}^{+}, \ldots v_{n}^{+}\right\}=\left\{\left(\begin{array}{l}
\max \\
i
\end{array} v_{i j}, j \in J\right)\left(\begin{array}{l}
\min \\
i
\end{array} v_{i j}, j \in \grave{J}\right)\right\}, i=1,2, \ldots m \\
& A^{-}=\left\{v_{1}^{-}, \ldots v_{n}^{-}\right\}=\left\{\left({ }_{i}^{\min } v_{i j}, j \in J\right)\left({ }_{i}^{\max } v_{i j}, j \in \grave{J}\right)\right\}, i=1,2, \ldots m
\end{aligned}
$$

Within this context, $v_{i j}$ is the weights of the factors. $A^{+}$defines the positive ideal value set whereas $A^{-}$provides information about the negative ideal value set (Noureddine and Ristic 2019). However, $J$ is associated with the benefit criteria and $\grave{J}$ with cost criteria (Zienba et al., 2020).

$$
\begin{aligned}
D_{i}^{+} & =\sqrt{\sum_{i=1}^{m}\left(v_{i}-A_{i}^{+}\right)^{2}} \\
D_{i}^{-} & =\sqrt{\sum_{i=1}^{m}\left(v_{i}-A_{i}^{-}\right)^{2}} \\
C C_{i} & =\frac{D_{i}^{-}}{D_{i}^{+}+D_{i}^{-}}
\end{aligned}
$$

\section{IT2F-VIKOR}

The VIKOR methodology is also considered to rank the alternatives. In the first step, a fuzzy decision matrix is generated with the help of the same procedure of IT2 fuzzy TOPSIS. Then, the fuzzy best value $\tilde{f}_{j}^{*}$ and fuzzy worst value $\tilde{f}_{j}^{-}$are calculated using Eq. (33). 


$$
\tilde{f}_{J}^{*}=\max _{i} \tilde{x}_{i j} \text {, and } \tilde{f}_{j}^{-}=\min _{i} \tilde{x}_{i j}
$$

In the following step, the mean group utility and maximal regret are computed as in Eqs. (34) and (35), respectively.

$$
\begin{gathered}
\tilde{S}_{i}=\sum_{i=1}^{n} \tilde{w}_{j} \frac{\left(\left|\tilde{f}_{j}^{*}-\tilde{x}_{i j}\right|\right)}{\left(\left|\tilde{f}_{j}^{*}-\tilde{f}_{j}^{-}\right|\right)} \\
\tilde{R}_{i}=\max _{j}\left[\tilde{w}_{j} \frac{\left(\left|\tilde{f}_{j}^{*}-\tilde{x}_{i j}\right|\right)}{\left(\left|\tilde{f}_{j}^{*}-\tilde{f}_{j}^{-}\right|\right)}\right]
\end{gathered}
$$

In these equations, $\tilde{w}_{j}$ represents the fuzzy weights, while $\tilde{S}_{i}$ is Ai regarding all criteria calculated by the total of the distance for the fuzzy best value. On the other side, $\tilde{R}_{i}$ is Ai with respect to the $j$-th criterion, which can be calculated by the maximum distance of the fuzzy best value. Next, the value of $\tilde{Q}_{i}$ is calculated using Eq. (36).

$$
\tilde{Q}_{i}=v\left(\tilde{S}_{i}-\tilde{S}^{*}\right) /\left(\tilde{S}^{-}-\tilde{S}^{*}\right)+(1-v)\left(\tilde{R}_{i}-\tilde{R}^{*}\right) /\left(\tilde{R}^{-}-\tilde{R}^{*}\right)
$$

In this framework, $v$ identifies the weight of the strategy of maximum group utility. Moreover, $1-v$ shows the weight of the individual regret. In this study, $v$ is accepted as 0.5 . In the final stage, the values of $S, R$, and $Q$ are calculated, which are used to rank the alternatives. With respect to checking the final ranks, two conditions should be satisfied. The first condition is related to the acceptable advantage shown in Eq. (37).

$$
Q\left(A^{(2)}\right)-Q\left(A^{(1)}\right) \geq 1 /(j-1)
$$

The second condition focused on the acceptable stability in the decision-making process. When one of the conditions is not satisfied, different conditions are taken

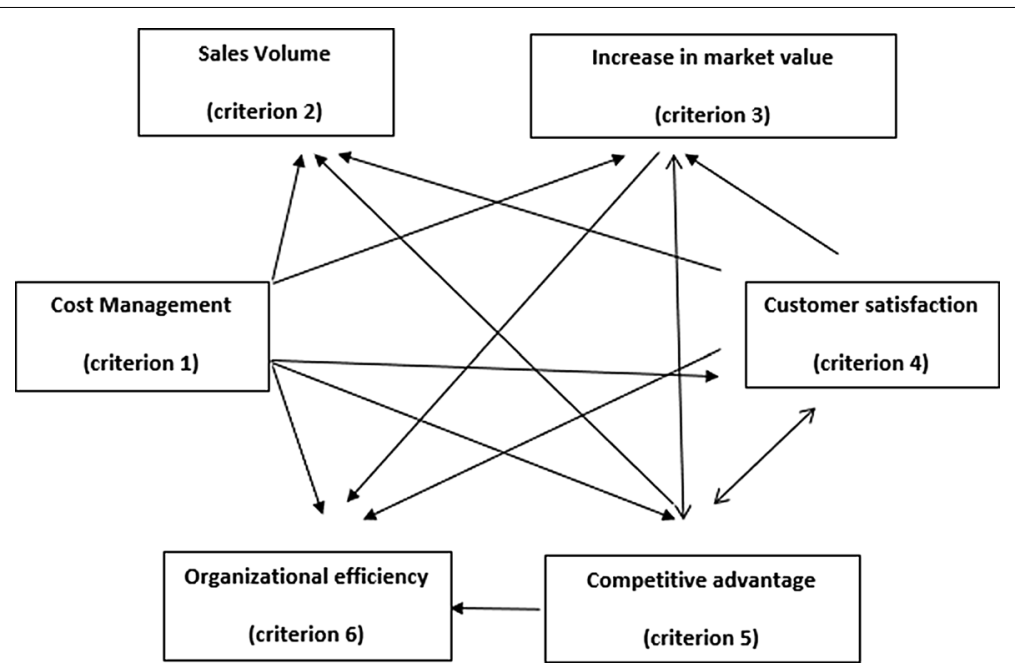

Fig. 3 Impact and relation map of fintech-based determinants. Source: Created by the authors 
Table 7 Closeness coefficient and ranking results for the alternatives. Source: Author's calculations

\begin{tabular}{lllll}
\hline Alternatives & $\mathbf{D}^{+}$ & $\mathbf{D}^{-}$ & $\begin{array}{l}\text { Closeness } \\
\text { coefficient }\end{array}$ & Ranking \\
\hline Money transferring (alternative 1) & 0.18 & 0.99 & 0.85 & 2 \\
Payments (alternative 2) & 0.03 & 1.12 & 0.97 & 1 \\
Savings (alternative 3) & 1.14 & 0.00 & 0.00 & 5 \\
Budgeting (alternative 4) & 0.99 & 0.18 & 0.16 & 4 \\
Borrowings (alternative 5) & 0.67 & 0.51 & 0.43 & 3 \\
\hline
\end{tabular}

Table 8 Ranking results with sensitivity analysis

\begin{tabular}{lllllll}
\hline Alternatives & Case 1 & Case 2 & Case 3 & Case 4 & Case 5 & Case 6 \\
\hline Money transferring (alternative 1) & 2 & 2 & 2 & 2 & 2 & 2 \\
Payments (alternative 2) & 1 & 1 & 1 & 1 & 1 & 1 \\
Savings (alternative 3) & 5 & 5 & 5 & 5 & 5 & 5 \\
Budgeting (alternative 4) & 4 & 4 & 4 & 3 & 3 & 4 \\
Borrowings (alternative 5) & 3 & 3 & 3 & 4 & 4 & 3 \\
\hline
\end{tabular}

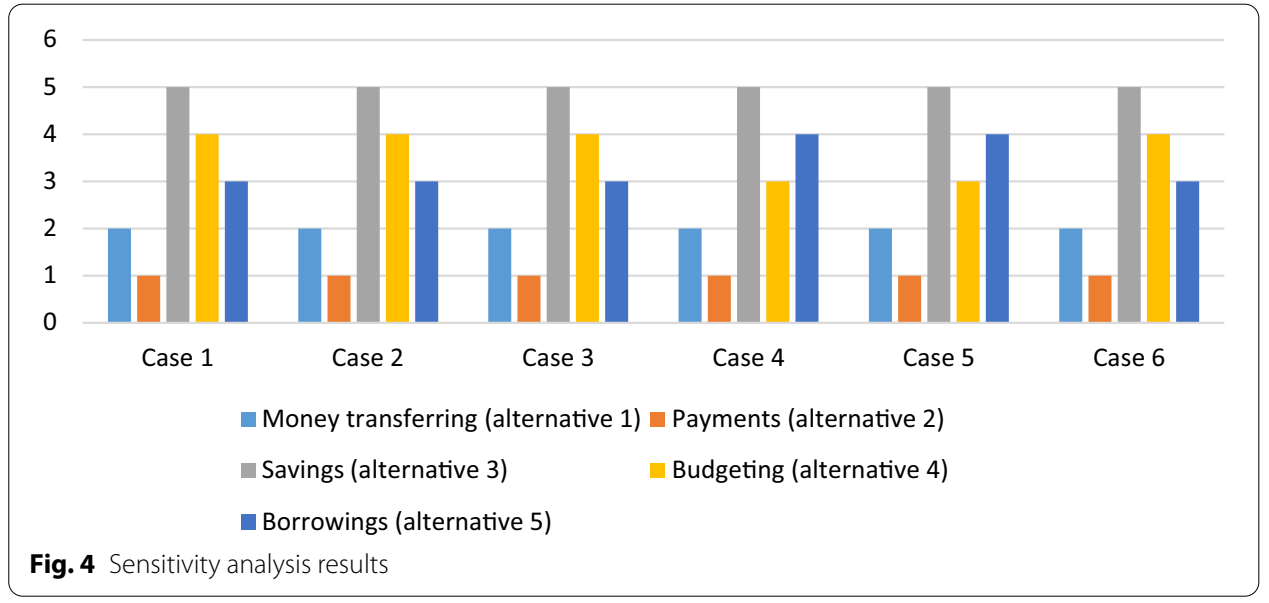

Table 9 Comparative ranking results

\begin{tabular}{lll}
\hline Alternatives & IT2F-TOPSIS & IT2F-VIKOR \\
\hline Money transferring (alternative 1) & 2 & 2 \\
Payments (alternative 2) & 1 & 1 \\
Savings (alternative 3) & 5 & 4 \\
Budgeting (alternative 4) & 4 & 5 \\
Borrowings (alternative 5) & 3 & 3 \\
\hline
\end{tabular}

into consideration. If the second condition is not satisfied, then it means the solution is composed of alternatives $A^{(1)}$ and $A^{(2)}$. If the first condition is not satisfied, then the alternatives $A^{(1)}, A^{(2)} \ldots, A^{(M)}$ are used. 


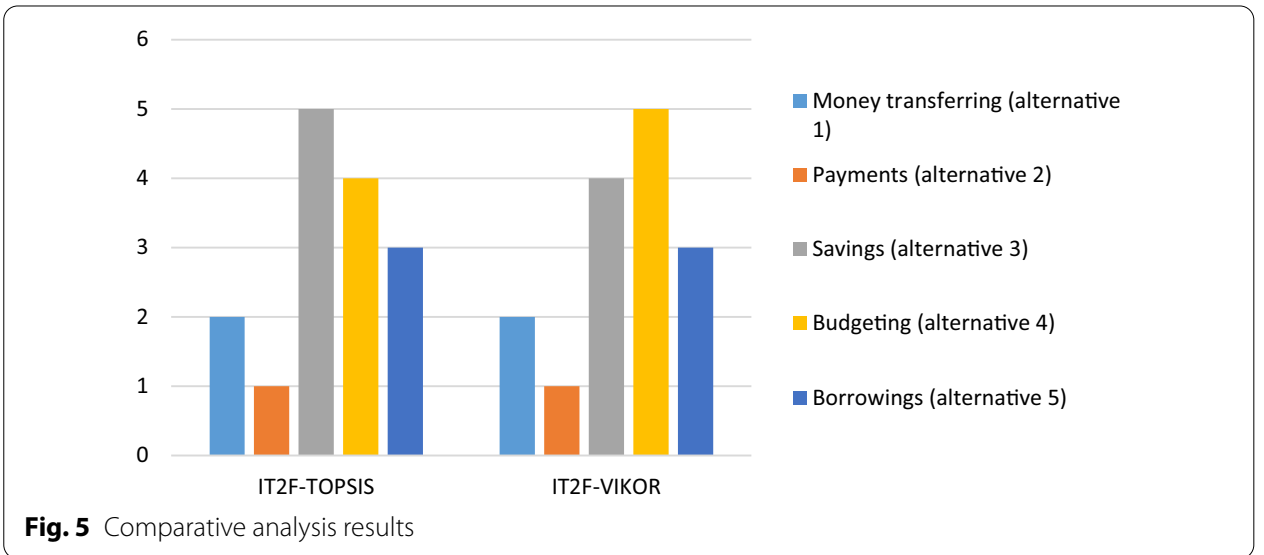

\section{Empirical findings}

This section presents our empirical findings of weights and ranking of suggested alternatives. First, we calculated the initial direct-relation matrix for the criteria (Table 11 of "Appendix B"). The total relation matrix and the defuzzified values are presented in Table 12 of "Appendix B". Table 6 below reports the weighting results for the dimensions and criteria, which are calculated by studying the values of $\tilde{D}_{i}^{\text {def }}, \tilde{R}_{i}^{\text {def }}$, and $\left(\tilde{D}_{i}+\tilde{R}_{i}\right)^{d e f}$ from the defuzzified matrix.

Our findings in Table 6 demonstrate that competitive advantage (criterion 5) is the most important factor among the Fintech-based determinants, while sales volume (criterion 2) is identified as having the weakest importance. Weighting results of the criteria can be listed as competitive advantage (criterion 5), cost management (criterion 1), customer satisfaction (criterion 4), increase in market value (criterion 3), organizational efficiency (criterion 6), and sales volume (criterion 2), respectively. The sum scores of each dimension suggests that non-financial factors are more important than the financial factors defining the Fintech-based determinants.

The impact-relation directions among the six criteria are illustrated in Fig. 3. According to the findings, sales volume (criterion 2) has no impact on the other criteria as none affect cost management (criterion 1). Cost management (criterion 1) has the strongest influence on the other criteria, while increase in market value (criterion 3 ) is the second weakest factor following sales volume.

The final step of the TOPSIS method is to calculate the ranking scores with the help of Eqs. (20)-(23). In this respect, values of $\mathrm{D}^{+}, \mathrm{D}^{-}$, and closeness coefficient are computed. The values of the closeness coefficient are listed in decreasing order. The ranking results of the suggested alternatives are reported in Table 7.

We also checked our results for consistency by employing a sensitivity analysis with six cases. The weights of the criteria are changed consecutively, and the rankings are reported with the changed weighting results. The findings are presented in Table 8.

The results of the sensitivity analysis are introduced in Fig. 4.

Sensitivity analysis results illustrate that the weighting priorities of the criteria are almost consistent for all cases. Moreover, a comparative analysis is applied for 
robustness check with the help of the IT2F-VIKOR method. The ranking results of both methods are presented in Table 9.

Furthermore, Fig. 5 illustrates the comparative evaluation results.

The results for IT2F-TOPSIS and the IT2F-VIKOR are similar. This is clear evidence that the proposed hybrid model is applicable for the extensions of TOPSIS and VIKOR with the IT2 fuzzy sets.

The ranking results are listed as payments (alternative 2), money transferring (alternative 1), borrowings (alternative 5), budgeting (alternative 4), and savings (alternative 3 ). Accordingly, the overall results reveal that payments (alternative 2) are the strongest Fintech-based investment alternative, while savings (alternative 3) is the weakest for European banking services. Our empirical findings suggest that European banks should mainly focus on payment alternatives for Fintech-based investments to attract more customers. Consistent with Guo and Liang (2016) and Du et al. (2019), this may suggest that bank customers prefer easily accessible and user-friendly payment systems.

Furthermore, consistent with Yao et al. (2018a, b) and Ramos-de-Luna et al. (2016), our findings illustrate that money transferring is another important Fintech-based investment alternative. Banks play a key role in money transferring systems and Fintechbased investments can help banks to decrease their operational costs. In addition, this is expected to increase customer satisfaction in terms of competitive advantage and in return increase banks' sales volume.

\section{Conclusion and future research}

This study evaluates Fintech-based investments of European banking services. To achieve this objective, we select three financial and three non-financial criteria based on the relevant literature and define five Fintech-based investment alternatives. Our empirical analysis employs the IT2 fuzzy DEMATEL method to weight the criteria and the IT2 fuzzy TOPSIS method to rank the investment alternatives. A consistency check is accomplished by applying the VIKOR method. Furthermore, a sensitivity analysis is conducted for six individual cases to check the coherency and reliability of the empirical findings.

Results of the IT2 fuzzy DEMATEL approach indicate that "competitive advantage" is the most important factor among the Fintech-based determinants while "sales volume" has the weakest importance in the criterion set. Moreover, non-financial factors are found to be more important than financial factors in defining the Fintech-based determinants. Looking at the impact and relations map, we observe that "cost management" is the most influencing criterion and "sales volume" does not have an impact on others. Moreover, the results of IT2 fuzzy TOPSIS suggest payments and money transferring as the most important Fintech investment alternatives. Based on our empirical findings, we first suggest that European banks should mainly focus on payment alternatives for Fintech investments to attract customers' attention and achieve effective collection of receivables. Second, Fintech investments in money transferring could help banks to decrease their costs, which is expected to have a positive influence on their sales volume. Our findings are consistent with studies such as Koomson and Ibrahim (2018), Azemi et al. (2019), Asamoah et al. (2020), Mensah et al. (2020), Gupta et al. (2019), Stulz (2019), and Yao et al. (2018a, b). 
Moreover, spillover effects should also be taken into consideration while generating appropriate strategies to improve Fintech investments. Due to globalization, there has been significant expansion in financial markets (Jahmane and Gaies 2020). Fan et al. (2020) argued that this resulted in an increased economic and financial commitment of countries to each other. This is an indication that individual countries' economies become more sensitive to problems experienced in other countries (Yin et al. 2020). National policies may not be very effective in certain situations such as Fintech investments. The results obtained herein are valid assuming that there are no serious global problems (Hofmann and Sertori 2020).

The main limitation of this study is that it focuses solely on the important points of Fintech-based investments and there are no industrial applications. We suggest a case evaluation in the banking sector for future research. Focusing on one country can help to provide direct recommendations to improve the financial system of that specific country. In addition, from the methodology side, empirical findings can be compared with other similar methods to understand the differences between quantitative data and expert opinions.

\section{Appendix A}

See Table 10.

Table 10 Evaluation scales for the criteria and alternatives. Source: Adapted from Chen and Lee (2010), Baykasoğlu and Gölcük (2017) and Dincer and Yuksel (2019)

\begin{tabular}{lll}
\hline Alternative evaluations & Criterion evaluations & Interval type 2 fuzzy numbers \\
\hline Very poor (VP) & Very low $(\mathrm{VL})$ & $((0,0,0,0.1 ; 1,1),(0,0,0,0.05 ; 0.9,0.9))$ \\
Poor (P) & Low $(\mathrm{L})$ & $((0,0.1,0.1,0.3 ; 1,1),(0.05,0.1,0.1,0.2 ; 0.9,0.9))$ \\
Medium poor (MP) & Medium low $(\mathrm{ML})$ & $((0.1,0.3,0.3,0.5 ; 1,1),(0.2,0.3,0.3,0.4 ; 0.9,0.9))$ \\
Fair (F) & Medium $(\mathrm{M})$ & $((0.3,0.5,0.5,0.7 ; 1,1),(0.4,0.5,0.5,0.6 ; 0.9,0.9))$ \\
Good (G) & Medium high $(\mathrm{MH})$ & $((0.5,0.7,0.7,0.9 ; 1,1),(0.6,0.7,0.7,0.8 ; 0.9,0.9))$ \\
Very good (VG) & High (H) & $((0.7,0.9,0.9,1 ; 1,1),(0.8,0.9,0.9,0.95 ; 0.9,0.9))$ \\
Best (B) & Very high $(\mathrm{VH})$ & $((0.9,1,1,1 ; 1,1),(0.95,1,1,1 ; 0.9,0.9))$ \\
\hline
\end{tabular}

\section{Appendix B}

See Tables 11 and 12 . 


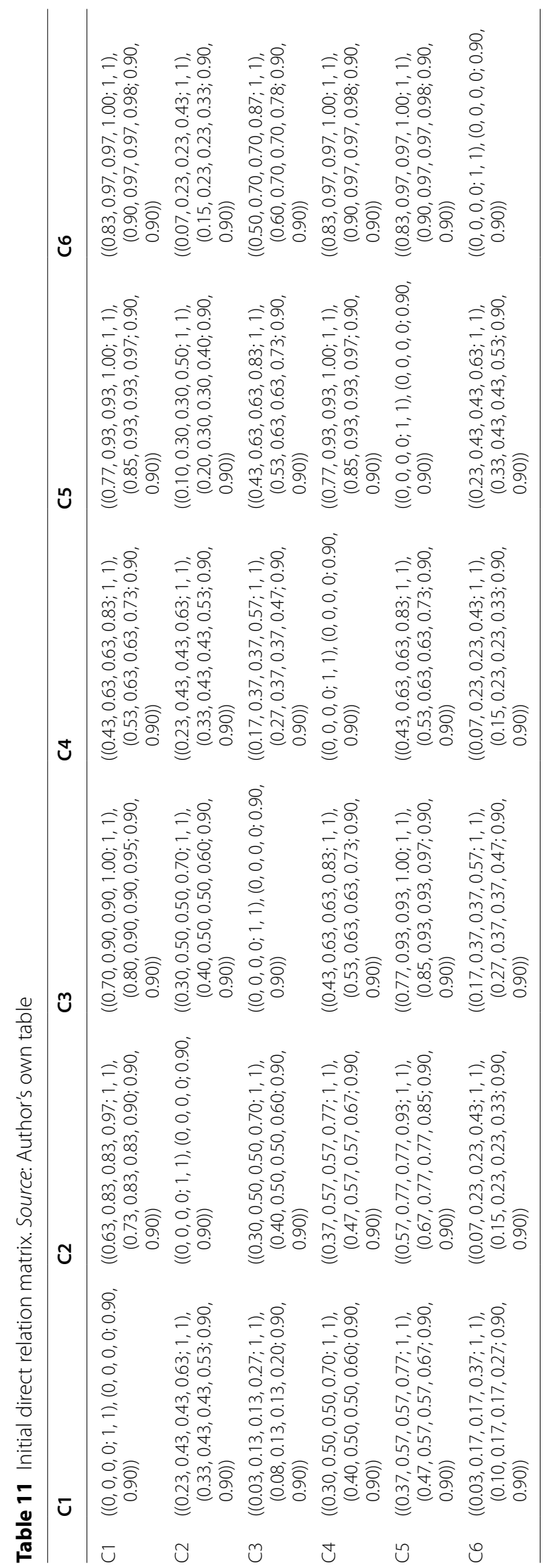


Table 12 Defuzzified total relation matrix. Source: Author's own table

\begin{tabular}{lllllll}
\hline & C1 & C2 & C3 & C4 & C5 & C6 \\
\hline C1 & 0.16 & 0.37 & 0.41 & 0.30 & 0.40 & 0.45 \\
C2 & 0.17 & 0.13 & 0.23 & 0.19 & 0.20 & 0.20 \\
C3 & 0.13 & 0.23 & 0.15 & 0.18 & 0.26 & 0.29 \\
C4 & 0.23 & 0.30 & 0.34 & 0.17 & 0.37 & 0.42 \\
C5 & 0.24 & 0.34 & 0.39 & 0.29 & 0.22 & 0.42 \\
C6 & 0.10 & 0.15 & 0.18 & 0.13 & 0.18 & 0.12 \\
\hline
\end{tabular}

\section{Appendix C}

See Tables 13, 14 and 15 


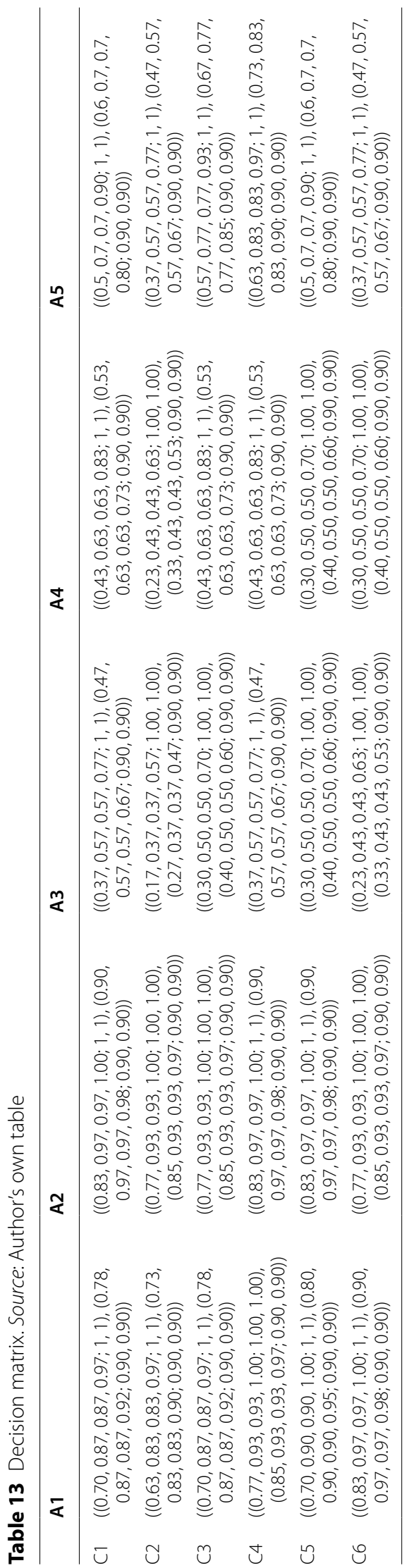


Table 14 Defuzzified decision matrix. Source: Author's own table

\begin{tabular}{llllll}
\hline & A1 & A2 & A3 & A4 & A5 \\
\hline C1 & 8.86 & 9.47 & 7.07 & 7.47 & 7.87 \\
C2 & 8.64 & 9.25 & 5.87 & 6.27 & 7.07 \\
C3 & 8.86 & 9.25 & 6.67 & 7.47 & 8.26 \\
C4 & 9.25 & 9.47 & 7.07 & 7.47 & 8.64 \\
C5 & 9.03 & 9.47 & 6.67 & 6.67 & 7.87 \\
C6 & 9.47 & 9.25 & 6.27 & 6.67 & 7.07 \\
\hline
\end{tabular}

Table 15 Weighted decision matrix. Source: Author's own table

\begin{tabular}{llllll}
\hline & $\mathbf{A 1}$ & $\mathbf{A 2}$ & $\mathbf{A 3}$ & $\mathbf{A 4}$ & A5 \\
\hline $\mathrm{C} 1$ & 1.53 & 1.63 & 1.22 & 1.29 & 1.36 \\
$\mathrm{C} 2$ & 1.25 & 1.34 & 0.85 & 0.91 & 1.03 \\
$\mathrm{C} 3$ & 1.44 & 1.50 & 1.08 & 1.21 & 1.34 \\
$\mathrm{C} 4$ & 1.58 & 1.62 & 1.21 & 1.28 & 1.48 \\
$\mathrm{C} 5$ & 1.77 & 1.86 & 1.31 & 1.31 & 1.54 \\
$\mathrm{C} 6$ & 1.45 & 1.42 & 0.96 & 1.02 & 1.08 \\
\hline
\end{tabular}

\section{Acknowledgements}

Not applicable.

\section{Authors' contributions}

SY wrote the methodology section and analyzed the data. HD collected the data and interpreted the results. ÖOA was a major contributor in writing the manuscript. GK successfully restructured and edited the manuscript to its final version. All authors read and approved the final manuscript.

\section{Funding}

Not applicable.

\section{Availability of data and materials}

All data generated or analyzed during this study are included in this article.

\section{Declarations}

\section{Competing interests}

The authors declare that they have no competing interests.

\section{Author details}

${ }^{1}$ School of Business Administration, Southwestern University of Finance and Economics, Chengdu 611130, China.

${ }^{2}$ College of Administrative Sciences and Economics, Koç University, Rumeli Feneri Yolu, Sarıyer, Istanbul 34450, Turkey.

${ }^{3}$ School of Business, Istanbul Medipol University, Kavacık Campus, Beykoz, Istanbul 34810, Turkey.

Received: 6 January 2021 Accepted: 12 May 2021

Published online: 21 May 2021

\section{References}

Anderson RG, Bordo M, Duca JV (2017) Money and velocity during financial crises: from the great depression to the great recession. J Econ Dyn Control 81:32-49

Arner DW, Barberis J, Buckley RP (2018) RegTech: Building a better financial system. In: Handbook of blockchain, digital finance, and inclusion 1: cryptocurrency, fin tech, insure tech and regulation. Academic Press

Asamoah D, Takieddine S, Amedofu M (2020) Examining the effect of mobile money transfer (MMT) capabilities on business growth and development impact. Inf Technol Dev 26:146-161

Azemi Y, Ozuem W, Howell KE, Lancaster G (2019) An exploration into the practice of online service failure and recovery strategies in the Balkans. J Buss Res 94:420-431

Bakar NA, Rosbi S (2018) Robust framework diagnostics of blockchain for Bitcoin transaction system: a technical analysis from Islamic financial technology (i-FinTech) perspective. Int J Bus Manag 2:22-29 
Baykasoğlu A, Gölcük I (2017) Development of an interval type-2 fuzzy sets based hierarchical MADM model by combining DEMATEL and TOPSIS. Exp Syst Appl 70:37-51

Çalık A (2021) A novel Pythagorean fuzzy AHP and fuzzy TOPSIS methodology for green supplier selection in the Industry 4.0 era. Soft Comptg 25:2253-2265

Căpraru B, Ihnatov I, Pintilie NL (2020) Competition and diversification in the European banking sector. Res Int Bus Finance 51:100963

Chang R, Fernández A, Gulan A (2017) Bond finance, bank credit, and aggregate fluctuations in an open economy. J Monet Econ 85:90-109

Chen K (2018) Financial innovation and technology firms: a smart new world with machines. Banking and finance issues in emerging markets. Emerald Publishing Limited, Bingley

Chen SM, Lee LW (2010) Fuzzy multiple attributes group decision-making based on the interval type-2 TOPSIS method. Exp Syst Appl 37:2790-2798

Chen P, Wu H (2019) The research on development status of China's consumer finance under the background of financial technology. In: 3rd International seminar on education innovation and economic management. Atlantis Press

Cornaggia J, Mao Y, Tian X, Wolfe B (2015) Does banking competition affect innovation? J Financ Econ 115:189-209

Demirel NÇ, Deveci M, Eser G (2016) Comparative analysis of fuzzy multi-criteria decision making for location selection of Textile plant in Turkey. In: Proceedings of international academy conference (No. 4006524). International Institute of Social and Economic Sciences

Deveci M, Cali U, Kucuksari S, Erdogan N (2020) Interval type-2 fuzzy sets based multi-criteria decision-making model for offshore wind farm development in Ireland. Energy 198:117317

Dhiman HS, Deb D (2020) Fuzzy TOPSIS and fuzzy COPRAS based multi-criteria decision making for hybrid wind farms. Energy 202:117755

Dinçer H, Yüksel S, Martinez L (2019) Interval type 2-based hybrid fuzzy evaluation of financial services in E7 economies with DEMATEL-ANP and MOORA methods. Appl Soft Comput 79:186-202

Dincer H, Yuksel S (2019) IT2-based fuzzy hybrid decision making approach to soft computing. IEEE Access 7:15932-15944

Dogan O, Deveci M, Canıtez F, Kahraman C (2019) A corridor selection for locating autonomous vehicles using an interval-valued intuitionistic fuzzy AHP and TOPSIS method. Soft Comput. https://doi.org/10.1007/ s00500-019-04421-5

Du WD, Pan SL, Leidner DE, Ying W (2019) Affordances, experimentation and actualization of FinTech: a blockchain implementation study. J Strateg Inf Syst 28:50-65

Du L, Dinçer H, Ersin I, Yüksel S (2020) IT2 fuzzy-based multidimensional evaluation of coal energy for sustainable economic development. Energy 13:2453

Dula C, Lee DLK (2017) Reshaping the financial order. In: Handbook of blockchain, digital finance, and inclusion, vol 1. Research Collection Lee Kong Chian School of Business, pp 1-18

Eyal I (2017) Blockchain technology: transforming libertarian cryptocurrency dreams to finance and banking realities. Computer 50:38-49

Fan H, Gou Q, Peng Y, Xie W (2020) Spillover effects of capital controls on capital flows and financial risk contagion. J Int Money Finance 105:102189

Farooque M, Jain V, Zhang A, Li Z (2020) Fuzzy DEMATEL analysis of barriers to Blockchain-based life cycle assessment in China. Comput Ind Eng 147:106684

Feng C, Ma R (2020) Identification of the factors that influence service innovation in manufacturing enterprises by using the fuzzy DEMATEL method. J Clean Prod 253:120002

Ferrari R (2016) FinTech impact on retail banking-from a universal banking model to banking verticalization. In: Chishti S, Barberis J (eds) The finTech book: the financial technology handbook for investors, enterpre and vision. Wiley, London, pp 248-252

Firmansyah EA, Anwar M (2019) Islamic financial technology (Fintech): its challenges and prospect. In: Achieving and sustaining SDGs 2018 conference: harnessing the power of frontier technology to achieve the sustainable development goals. Atlantis Press

Firmansyah HB, Ramdani AL (2018) The role of Islamic financial technology (FinTech) start-up in improving financial inclusion in Indonesia case: Angsur (May 27, 2018). In: 3rd international conference of integrated intellectual community (ICONIC) 2018

Garg CP (2021) Modeling the e-waste mitigation strategies using Grey-theory and DEMATEL framework. J Clean Prod 281:124035

Gozman D, Liebenau J, Mangan J (2018) The innovation mechanisms of fintech start-ups: insights from SWIFT's innotribe competition. J Manag Inf Syst 35:145-179

Guo Y, Liang C (2016) Blockchain application and outlook in the banking industry. Financ Innov 2:24

Gupta KP, Manrai R, Goel U (2019) Factors influencing adoption of payments banks by Indian customers: extending UTAUT with perceived credibility. J Asia Bus Stud 13:173-195

Heiskanen A (2017) The technology of trust: how the Internet of Things and blockchain could usher in a new era of construction productivity. Constr Res Innov 8:66-70

Hofmann E, Sertori Y (2020) Financial spillover effects in supply chains: do customers and suppliers really benefit? Logistics 4:6-22

Jahmane A, Gaies B (2020) Corporate social responsibility, financial instability and corporate financial performance: linear, non-linear and spillover effects - the case of the CAC 40 companies. Finance Res Lett 34:101483

Kabakova O, Plaksenkov E, Korovkin V (2016) Strategizing for financial technology platforms: findings from four Russian case studies. Psychol Mark 33:1106-1111

Kauffman RJ, Liu J, Ma D (2015) Innovations in financial IS and technology ecosystems: high-frequency trading in the equity market. Technol Forecast Soc Change 99:339-354

Kazan E, Tan CW, Lim ET, Sørensen C, Damsgaard J (2018) Disentangling digital platform competition: the case of UK mobile payment platforms. J Manag Inf Syst 35:180-219 
Ko T, Lee J, Ryu D (2018) Blockchain technology and manufacturing industry: real-time transparency and cost savings. Sustainability 10:4274

Komulainen H, Saraniemi S, Ulkuniemi P, Ylilehto M (2018) End-customer value restructuring the financial service supply chain. Mark Intell Plan 36:709-720

Koomson I, Ibrahim M (2018) Financial inclusion and growth of non-farm enterprises in Ghana. In: Efobi U, Asongu S (eds) Financing sustainable development in Africa. Palgrave Macmillan, Cham

Kumar R, Khan Al, Abushark YB, Alam MM, Agrawal A, Khan RA (2020) An integrated approach of fuzzy logic, AHP and TOPSIS for estimating usable-security of web applications. IEEE Access 8:50944-50957

Lee I, Shin YJ (2018) Fintech: ecosystem, business models, investment decisions, and challenges. Bus Horiz 6:35-46

Li X, Jiang P, Chen T, Luo X, Wen Q (2017) A survey on the security of blockchain systems. Future Gener Comput Syst 107:841-853

Lin C, Kou G, Peng Y, Alsaadi FE (2020) Aggregation of the nearest consistency matrices with the acceptable consensus in AHP-GDM. Ann Oper Res. https://doi.org/10.1007/s10479-020-03572-1

Liu J, Kauffman RJ, Ma D (2015) Competition, cooperation, and regulation: understanding the evolution of the mobile payments technology ecosystem. Electron Commer Res Appl 14:372-391

Mathew M, Chakrabortty RK, Ryan MJ (2020) A novel approach integrating AHP and TOPSIS under spherical fuzzy sets for advanced manufacturing system selection. Eng Appl Artif Intell 96:103988

Melin P, Soto J, Castillo O, Soria J (2012) A new approach for time series prediction using ensembles of ANFIS models. Expert Syst Appl 39:3494-3506

Mensah IK, Chuanyong L, Zeng G (2020) Factors determining the continued intention to use mobile money transfer services (MMTS) among university students in Ghana. Int J Mob Hum Comput Interact 12:1-21

Mittal S, Pant A, Bhadauria SS (2017) An empirical study on customer preference towards payment banks over universal banks in Delhi NCR. Proc Comp Sci 122:463-470

Moden N, Neufeld P (2020) How Covid-19 has sped up digitalization for the banking sector

Nguyen QK (2016) Blockchain-a financial technology for future sustainable development. In: 2016 3rd International conference on green technology and sustainable development. IEEE, pp 51-54

Noureddine M, Ristic M (2019) Route planning for hazardous materials transportation: multicriteria decision making approach. Decis Mak Appl Manag Eng 2:66-85

Petrovic I, Kankaras M (2020) A hybridized IT2FS-DEMATEL-AHP-TOPSIS multicriteria decision making approach: case study of selection and evaluation of criteria for determination of air traffic control radar position. Decis Mak: Appl Manag Eng 3:146-164

Pulido M, Melin P, Castillo O (2014) Particle swarm optimization of ensemble neural networks with fuzzy aggregation for time series prediction of the Mexican Stock Exchange. Inf Sci 28:188-204

Qiu D, Dinçer H, Yüksel S, Ubay GG (2020) Multi-faceted analysis of systematic risk-based wind energy investment decisions in E7 economies using modified hybrid modeling with IT2 fuzzy sets. Energy 13:1423

Ramos-de-Luna I, Montoro-Ríos F, Liébana-Cabanillas F (2016) Determinants of the intention to use NFC technology as a payment system: an acceptance model approach. Inf Syst e-Bus Manag 14:293-314

Rani P, Mishra AR, Mardani A, Cavallaro F, Alrasheedi M, Alrashidi A (2020) A novel approach to extended fuzzy TOPSIS based on new divergence measures for renewable energy sources selection. J Clean Prod 257:120352

Rouyendegh BD, Yildizbasi A, Üstünyer P (2020) Intuitionistic fuzzy TOPSIS method for green supplier selection problem. Soft Comput 24:2215-2228

Rusydiana AS (2018) Developing Islamic financial technology in Indonesia. Has Econ Bus Rev 2:143-152

Shaikh AA, Hanafizadeh P, Karjaluoto H (2017) Mobile banking and payment system: a conceptual standpoint. Int J E-Bus Res 13:14-27

Soto J, Melin P, Castillo O (2014) Time series prediction using ensembles of ANFIS models with genetic optimization of interval type-2 and type-1 fuzzy integrators. Int J Hybrid Intell Syst 11:211-226

Soto J, Melin P, Castillo O (2018) A new approach for time series prediction using ensembles of IT2FNN models with optimization of fuzzy integrators. Int J Fuzzy Syst 20:701-728

Soto J, Castillo O, Melin P, Pedrycz W (2019) A new approach to multiple time series prediction using MIMO fuzzy aggregation models with modular neural networks. Int J Fuzzy Syst 21:1629-1648

Stulz RM (2019) Fintech, bigtech, and the future of banks. J Appl Corp Finance 31:86-97

Sun T (2018) Balancing innovation and risks in digital financial inclusion - experiences of ant financial services group. In: Handbook of blockchain, digital finance, and inclusion, vol 2. Academic Press, pp 37-43

Tan JD, Purba JT, Widjaya AE (2018) Financial technology as an innovation strategy for digital payment services in the millenial generation. In: 1st Aceh Global Conference. Atlantis Press

Thakor AV (2020) Fintech and banking: what do we know? J Finan Intermed 41:100833

The Fintech Revolution (2016) The Economist, The Economist Newspaper. www.economist.com/leaders/2015/05/09/ the-fintech-revolution

Thompson BS (2017) Can financial technology innovate benefit distribution in payments for ecosystem services and REDD+? Ecol Econ 139:150-157

Treleaven P, Brown RG, Yang D (2017) Blockchain technology in finance. Computer 50:14-17

Türk S, Deveci M, Özcan E, Canıtez F, John R (2021) Interval type-2 fuzzy sets improved by Simulated Annealing for locating the electric charging stations. Inf Sci 547:641-666

Wang C, Zhou H, Dınçer H, Yüksel S, Ubay GG, Uluer GS (2020) Analysis of electricity pricing in emerging economies with hybrid multi-criteria decision-making technique based on interval-valued intuitionistic hesitant fuzzy sets. IEEE Access 8:190882-190896

Woldmariam MF, Ghinea G, Atnafu S, Groenli TM (2016) Monetary practices of traditional rural communities in Ethiopia: Implications for new financial technology design. Hum Comput Interact 31:473-517

$X u Z$, Cheng X (2017) The impact of financial intelligence on commercial banking from the perspective of transaction cost. In: 2017 3rd international conference on economics, social science, arts, education and management engineering. Atlantis Press 
Xu C, Wu Y, Dai S (2020) What are the critical barriers to the development of hydrogen refueling stations in China? A modified fuzzy DEMATEL approach. Energy Policy 142:111495

Yao M, Di H, Zheng X, Xu X (2018a) Impact of payment technology innovations on the traditional financial industry: a focus on China. Technol Forecast Soc Change 135:199-207

Yao M, Di H, Zheng X, Xu X (2018b) Impact of payment technology innovations on the traditional financial industry: a focus on China. Technol Forecast Soc Change 135:199-207

Yin K, Liu Z, Jin X (2020) Interindustry volatility spillover effects in China's stock market. Phys A 539:122936

Yu D, Kou G, Xu Z (2021) Analysis of collaboration evolution in AHP research: 1982-2018. Int J Inf Technol Decis Mak 20:7-36

Yuan J, Zhang ZM, Yüksel S, Dinçer H (2020) Evaluating recognitive balanced scorecard-based quality improvement strategies of energy investments with the integrated hesitant 2-tuple interval-valued Pythagorean fuzzy decisionmaking approach to QFD. IEEE Access 8:171112-171128

Yucesan M, Gul M (2020) Hospital service quality evaluation: an integrated model based on Pythagorean fuzzy AHP and fuzzy TOPSIS. Soft Comput 24:3237-3255

Zhang M, Yang J (2019) Research on financial technology and inclusive finance development. In: 2018 6th international conference on economics, social science, arts, education and management engineering. Atlantis Press

Zhang G, Zhou S, Xia X, Yüksel S, Baş H, Dincer H (2020a) Strategic mapping of youth unemployment with interval-valued intuitionistic hesitant fuzzy DEMATEL based on 2-tuple linguistic values. IEEE Access 8:25706-25721

Zhang G, Zhou S, Xia X, Yüksel S, Baş H, Dincer H (2020b) Strategic mapping of youth unemployment with intervalvalued intuitionistic hesitant fuzzy DEMATEL based on 2-tuple linguistic values. IEEE Access 8:25706-25721

Zhong J, Hu X, Yüksel S, Dinçer H, Ubay GG (2020) Analyzing the investments strategies for renewable energies based on multi-criteria decision model. IEEE Access 8:118818-118840

Zhou X, Dong J, Zhang X, Zhang P (2018) Application of blockchain technology in the financial industry and its legal norms. In: 2018 2nd international conference on man, education and social science. Atlantis Press

Zhou P, Zhou P, Yüksel S, Dinçer H, Uluer GS (2020) Balanced scorecard-based evaluation of sustainable energy investment projects with it2 fuzzy hybrid decision making approach. Energy 13:82

Ziemba P, Becker A, Becker J (2020) A consensus measure of expert judgment in the fuzzy TOPSIS method. Symmetry 12:204-226

\section{Publisher's Note}

Springer Nature remains neutral with regard to jurisdictional claims in published maps and institutional affiliations.

\section{Submit your manuscript to a SpringerOpen ${ }^{\circ}$ journal and benefit from:}

- Convenient online submission

- Rigorous peer review

- Open access: articles freely available online

High visibility within the field

Retaining the copyright to your article

Submit your next manuscript at $\boldsymbol{\nabla}$ springeropen.com 